\title{
The Effect of Interviewers' Genders on the Quantity and Quality of Their Interviewees' Output: A Comparative Inquiry among Saudi Students
}

\author{
Ahmad I Alhojailan \\ Department of English Language and Translation \\ College of Arabic Language and Social Studies \\ Qassim University, Buraydah, Saudi Arabia
}

Received: June 2, 2020 Accepted: July 16, 2020 Published: July 20, 2020

doi:10.5296/ijele.v8i2.17377 URL: https://doi.org/10.5296/ijele.v8i2.17377

\begin{abstract}
Gender segregation is widely established in Saudi Arabia, and this may affect the interviewing dynamic in conducting spoken tests. Such an effect could pose significant consequences for interviewees; for example, it might affect their ability to obtain high scores in the speaking sections of standardized tests (e.g., the IELTS). This could prevent them from enrolling in universities in English speaking countries (e.g., United States, United Kingdom, Australia, New Zealand, and Canada) as well as other universities that require such tests for enrollment purposes. As such, this study attempts to explore whether the gender of an interviewer can affect how a respondent forms their answer in terms of both depth and length. In this study, two interviewers (a male and a female) interviewed six Saudis of both genders, comprising a total of 12 interviews. The results showed that when both the interviewer and the interviewee were of the same gender, interviewees' responses tended to be lengthy, and they were more likely to expand their response to other related topics. On the other hand, when both the interviewer and the interviewee were not of the same gender, brevity and/or avoidance characterized their answers.
\end{abstract}

Keywords: oral assessment, speaking skill, testing, Saudi Arabic speakers, gender, speaking, interviewees 


\section{MInstitute ${ }^{\text {Mech }}$}

\section{Introduction}

\subsection{Background}

Owing to the increasing number of students (both native and non-native speakers of English) enrolling in universities where the language of study is English (Institute of International Education, 2014), universities have started to ask that applicants take English language proficiency exams, such as the International English Language Testing System (IELTS) and the Test of English as a Foreign Language (TOEFL) as a requirement for enrolment. Additionally, "millions of students annually take a standardized test, as these are the most widely used college entrance exams" (Saygin, 2019, p. 1). Therefore, as these standardized tests can have either a positive or a negative effect on students' lives and futures, they must do their best to achieve the highest marks possible so that they can gain admission to universities for graduate and undergraduate studies.

The number of Saudi students who enroll in universities in countries where English is the first language is increasing (Alhojailan, 2015). These standardized tests, therefore, affect the future of an increasing number of people, and often the tests are administered across the boundaries of gender (i.e., men interview women and vice versa). Owing to religious and cultural reasons, interaction between men and women (who are not first-degree relatives) in Saudi Arabia is not that common. I hypothesize that, in the context of this far-reaching gender segregation, a Saudi female interviewed by a male examiner might see her results affected negatively, and I predict that this could be said for the opposite gender, too. These tests are eften pivotal for Saudi students, and therefore, I hold that it is important to secure an understanding of the effect that gender possibly has on their outcomes.

\subsection{Literature Review}

\subsubsection{The Presence of the Effect}

Although "interviewers vary considerably from each other in relation to their test behavior," which could be due to "gendered differences in communicative style" (O'Loughlin, 2002, p. 169 ), research focusing on the effects of their interviewer's gender on interviewees' responses has returned mixed findings.

At one end of this spectrum, there are studies that emphasize the effect elicited by the interviewer's gender. For example, in a 1976 study conducted by Rapoport and Rapoport, it was found that wives preferred to be interviewed by a male interviewer, and husbands preferred to be interviewed by a female interviewer. Since then, Galla, Frisone, Jeffrey, and Gaer (1981) have claimed that non-traditional responses were provided by both female and male interviewees when interviewed by a female interviewer. Lueptow, Moser, and Pendleton (1990) also argue that when female respondents are interviewed by another female, the effects are stronger. When it comes to language testing, several studies (e.g., Brown, 2003; Lumley \& O'Sullivan, 2005; O'Sullivan, 2000) report that gender plays a role in the scores obtained. Most recently, Namaziandost, Abedi, and Nasri (2019) have pointed out that gender differences affect, "students' performance concerning speaking accuracy and fluency" (p. 120). 
At the other end of this spectrum, there are several studies which have revealed that interviewers' genders have no effect on the responses of their interviewees. Johnson and Moore (1993), for example, claim that there is little evidence for such an effect. Touching on topics like gender equality, women's activism, abortion, affirmative action, and opinions on female political figures, Huddy et al. (1997) found that the interviewer's gender does not have any influence on their respondents' answers. Moreover, in an experiment which reconstructed the speaking section of the IELTS exam and tested 16 different international students (eight males and eight females) with eight accredited IELTS interviewers (four females and four males), O'Loughlin (2002) found that gender had no effect on the interviewees' output, nor on the ratings they received. Further, following the IELTS speaking section procedures with 160 Iranian students, Motallebzadeh and Nematizadeh (2011) claim that "gender plays not a very significant role in the oral assessment process" (p. 169). Finally, in the famous telephone survey study that was conducted by Kane and Macaulay (1993), it was found that although there were indications of a gendered influence on respondents' answers, the influence was not significant.

Concerning the effect of the interviewers' and interviewees' gender on the scores of the speaking section in IELTS, various studies report different findings. Some studies (e.g., Locke, 1984; Porter, 1991) report that interviewees who had male interviewers received better scores compared to those who had female interviewers. On the other hand, other studies (e.g., O'Sullivan, 2000) claim that those who had female interviewers received higher scores. Different from these two opposing sides, Buckingham (1997) reports that interviewees who had an interviewer of the same gender scored better.

In the Arab world, only two studies have attempted to understand the effect of the interviewer's gender on the discourse produced by their interviewees. Through a face-to-face survey conducted on 1,200 women in Egypt, Blaydes and Gillum (2010) found that participants' responses were indeed affected by their interviewer's gender. Second, Altakhaineh, AL-Tkhayneh, and Rahrouh (2019), by conducting interviews with 30 Emirati IELTS examinees (15 males and 15 females) and 10 non-native English speaking IELTS teachers, found that "the gender of the IELTS examiner can influence the performance of the examinees on the IELTS speaking test" (p. 48).

\subsubsection{Types of Effects}

Gender in such interviews could act in several directions. Huddy et al. (1997), for example, asserts that women are somewhat more likely than men to offer a feminist response to an interviewer who is a woman. In addition, reviewing the answers of 90 female college students in a town in the Western United States, Landis, Sullivan, and Sheley (1973) found statistically important evidence that female interviewers received more feminist responses. Conversely, Kane and Macaulay (1993) found that when male interviewees are interviewed by a female interviewer, more egalitarian responses are elicited.

Lamb and Garretson (2003) reviewed 672 forensic interviews of sexually abused children. The responses children provided varied depending on their gender and that of the interviewer. The children, according to the researchers, would be more responsive when interviewed by 
female interviewers, providing more allegation-related detail both overall and in response to open-ended questions.

On the one hand, some studies show that women, unlike men, tend to give feminist responses to female interviewers (Grimes \& Hansen, 1984; Lueptow, Moser, \& Pendleton, 1990). On the other hand, other studies demonstrate that male respondents appear more feminist when being interviewed by women (Ballou \& Del Boca, 1980). In addition, Catania, Binson, Canchola, Pollack, and Huack (1996) reveal that women are more willing to talk about sensitive topics such as sexual activity to a female interviewer.

One of the findings of the study conducted by Padfield and Procter (1996) is that the female interviewees talk to male interviewers more than they do to female interviewers (the averages in this study were 84 and 76 minutes, respectively).

It is clear that previous research has unearthed a number of effects regarding gender and its effect in the interviewing process. Table 1 provides a summary of all the types of effect perceived throughout the aforementioned studies.

Table. 1 A summary of the types of effects that gender has been found to have in an interviewing context

\begin{tabular}{|c|c|}
\hline Study & Types of Effect \\
\hline Huddy et al. (1997) & $\begin{array}{l}\text { Women were somewhat more likely than men to give a feminist } \\
\text { response to a female interviewer. }\end{array}$ \\
\hline Landis et al. (1973) & Female interviewers received more feminist responses. \\
\hline $\begin{array}{l}\text { Kane and Macaulay } \\
\text { (1993) }\end{array}$ & $\begin{array}{l}\text { When male interviewees were interviewed by a female } \\
\text { interviewer, more egalitarian responses were elicited. }\end{array}$ \\
\hline $\begin{array}{c}\text { Lamb and } \\
\text { Garretson (2003) }\end{array}$ & $\begin{array}{l}\text { Children were more responsive when interviewed by female } \\
\text { interviewers, providing more allegation-related detail overall and } \\
\text { in response to open-ended questions. }\end{array}$ \\
\hline $\begin{array}{l}\text { Grimes and Hansen } \\
\text { (1984) }\end{array}$ & $\begin{array}{l}\text { Women, unlike men, tended to provide feminist responses to } \\
\text { female interviewers. }\end{array}$ \\
\hline $\begin{array}{l}\text { Lueptow et al. } \\
\qquad(1990)\end{array}$ & $\begin{array}{l}\text { Women, unlike men, tended to provide feminist responses to } \\
\text { female interviewers. }\end{array}$ \\
\hline $\begin{array}{l}\text { Ballou and Del Boca } \\
\qquad(1980)\end{array}$ & $\begin{array}{l}\text { Male respondents appeared more feminist when interviewed by } \\
\text { female interviewers. }\end{array}$ \\
\hline Catania et al. (1996) & $\begin{array}{l}\text { Women were more willing to talk about sensitive topics such as } \\
\text { sexual activity with a female interviewer. }\end{array}$ \\
\hline $\begin{array}{l}\text { Padfield and Procter } \\
\qquad(1996)\end{array}$ & $\begin{array}{l}\text { Female interviewees talked to the male interviewer more than } \\
\text { they did to the female interviewer. }\end{array}$ \\
\hline
\end{tabular}




\subsubsection{Saudi Arabia}

Saudi Arabia is considered to be the largest Arab state in Western Asia by land area and the second largest in the Arab world. In Saudi Arabia, Islam is the official religion, and it determines all aspects of life there. Saudi Arabia is referred to as, "The Land of the Two Holy Mosques" because it is home to the two holiest places in Islam. The conservative law and customs of Islam play a defining role in Saudi society. Schools, for example, are segregated according to gender. Interaction between genders, therefore, is limited and takes place in only a few professions (e.g., the medical field). Alhojailan (2015) points out the following:

The educational system in Saudi Arabia consists of five stages: kindergarten (one-two years) for children at five and/or six years old, elementary school (six years) for students who are between 7-12 years old, intermediate school (three years) for students who are 13-15 years old, secondary school (three years) for students who are 16-18 years old, and university (four-six years depending on the major) for students who are 19-24 years old. With the exception of kindergarten, schools are segregated by gender. (p. 14)

The government of Saudi Arabia offers several scholarship programs. Such programs are aimed at supporting outstanding Saudi students to study abroad at the graduate and undergraduate level. The total number of Saudi students studying abroad is 122 531, and 51.6\% study in the United States of America, the United Kingdom, Canada, and Australia (Aboshaheen, 2020). Ensuring egalitarianism throughout the qualification process is, therefore, a matter of indisputable relevance to a large number of Saudi citizens and merits further investigation.

\subsection{Aim of the Study}

Previous research has drawn attention to the issue of potential gender influence in interview scenarios, but the possibility of such an influence among Saudi Arabic speakers has not been investigated. Therefore, this study seeks to fill this gap in the literature by attempting to answer the following questions:

1) Does the gender of an interviewer have an effect on the discourse produced by their interviewees?

2) If such a gender effect does exist, what is the type of effect/effects?

\section{Method}

\subsection{Instruments}

The nature of this study necessitates the use of interviews as the main instrument. Rubin and Rubin (2005) mention that the qualitative interview allows a researcher to find out how interviewees feel about and think of their worlds. They stipulate also that, via qualitative interview, the researcher can understand the experiences of their subjects even if they were not involved in those experiences. Miles and Huberman (1994) point out that the outcome of 
such an approach is more reliable since the data are captured in great detail and the answers provided and stances demonstrated by interviewees offer researchers a solid ground for their study. Furthermore, qualitative interviews, "allow a researcher to clarify ambiguous answers and, when appropriate, seek follow-up information" (Leedy \& Ormrod, 2015, p. 160). A final reason for not employing a quantitative data elicitation tool was that the type of data the researcher sought and which might provide potential answers to the research questions can only be elicited via a qualitative data elicitation tool (see Curtis, Murphy, \& Shields, 2014).

All the questions were generated by the researcher, and space was given to the interviewees to express their opinions and answers freely. In addition to gathering the interviewees' background information, the carefully structured set of questions covered the following areas: politics and women's rights (from Johnson \& Moore's 1993 study) and sports. These areas were chosen because they are gendered issues. Sports topics, for example, tend to be favored by males more than females, and the opposite can be said for topics related to women's rights. With regards to politics, the researcher chose this field because it is a field that is mostly not tackled by both young men and women in the country of the participants (Saudi Arabia). Finally, at the end of the interview, each interviewee was asked by an interviewer of the same gender (male=male, female=female) if they would have given different answers to the questions if they were interviewed by an interviewer of a different gender.

The interviews were in Arabic since the interviewers and the interviewees come from the same country. All interviews were tape-recorded and were 20 to 35 minutes in length for each participant with each interviewer. The interviews were informal and open-ended and carried out in a conversational style.

\subsection{Participant Characteristics}

The researchers used convenience sampling to recruit participants for this study. Although this type of sampling is not preferred by researchers as it means that findings cannot be generalized, it enables researchers to interview only those who are willing to take part in the study, particularly when variables such as proficiency are not required in the research (Mackey \& Gass, 2005).

The participants in this study are all Saudi males and females who came from different cities in Saudi Arabia. This was done to provide a cross section of the Saudi society, and hence, to confirm any findings obtained. In addition, the interviewees at the time of the study were undergraduate students from different streams. I ensured that the interviewers did not personally know the interviewees to avoid any misleading influence on our results. The interviewees were the friends of the researchers' friends. Although the interviewers did not meet the interviewees before conducting the interviews, they did their best to convey an impression of informality in the interviews. The interviewees were contacted via phone calls first, and signed a consent form before the interview. Table 2 provides more information about the sample selected. 
Table. 2 Information about the participants

\begin{tabular}{ccccc}
\hline No. & Name & Gender & Age & Degree \\
\hline $\mathbf{1}$ & Rakan & M & 19 & BA \\
\hline $\mathbf{2}$ & Lama & F & 24 & BA \\
\hline $\mathbf{3}$ & Murad & M & 19 & BA \\
\hline $\mathbf{4}$ & Hana & F & 21 & BA \\
\hline $\mathbf{5}$ & Hesham & M & 22 & BA \\
\hline $\mathbf{6}$ & Abeer & F & 20 & BA \\
\hline
\end{tabular}

Each interviewee was interviewed twice - once by the male researcher and once by a female assistant. Both interviewers had doctoral degrees in English and had taken the IELTS exam several times themselves for enrollment purposes. As there were six different interviewees (three females and three males), the total number of interviews conducted was 12 (six interviews with each interviewer).

\subsection{Interviewers' Bias}

The interviewers did their best to avoid any intervention that might positively or negatively affect the output of the interviewees during the interviewing process. For example, no overlaps were made by the interviewers during the interviewing process. Coates (2015) explains overlaps as follows:

Instances of slight over-anticipation by the next speaker: instead of beginning to speak immediately following current speaker's turn, the next speaker begins to speak at the very end of current speaker's turn, overlapping the last word (or part of it). (p. 109)

\section{Results and Discussion}

As stated earlier, this research seeks answers to the following research questions:

1) Does the gender of an interviewer have an effect on the discourse produced by their interviewees?

2) If such a gender effect does exist, what is the type of effect/effects?

Regarding the first research question, the interviews revealed a difference in the participants' responses to each of the interviewers. The interviews were analyzed, and differences were noted in three areas: the length of participants' answers, the depth of their answers, and their answer to the last question of the interview.

By comparing participants' answers in response to the same question, it was found that avoidance was dominant. Interviewees would talk at length about certain topics with the interviewer of the same gender as they and would provide short answers or indicate their 
disinterest in the same topic when interviewed by the interviewer of the opposite gender. For example, Rakan (one of the male participants) engaged with the male interviewer on the topic of politics. His response spanned several topics in politics, including the American elections, as well as the political climate in Syria, Iran, and Lebanon. Conversely, when interviewed by the female interviewer, he mentioned only that he watched the elections to engage in conversations with native speakers to help him in learning English. Moreover, he told the female interviewer that he had no interest in politics.

In addition, Hesham (another male interviewee), responding to a question about his interest in soccer as a sport, generated a lively discussion with the male interviewer. He talked about his favorite national and international teams, and his reasons for choosing to support those teams. On the other hand, in response to the female interviewer, he mentioned only that he liked to watch soccer but did not mention any information about his favorite teams. Moreover, when Murad (another male interviewee) was asked if he liked to play soccer, his answer to the female interviewer was as follows:

"I can't play. I have asthma. I only like to watch games." (Murad, Interview Transcript, p. 7).

However, when the same interviewee was asked the same question by the male interviewer, he replied as follows:

"I can't play soccer because I have asthma. However, I like watching games. I like to watch Barcelona plays because they really play well. It is my favorite team.” (Murad, Interview Transcript, p. 15).

As can be seen from the two cases relayed above, the answers to the female interviewer given by male interviewees comprised only a few short sentences of simple structure compared with those of the same interviewee engaging with a male interviewer.

This behavior could be attributed to the effect of the interviewees' culture, which is heavily segregated in terms of gender. The male interviewees might have felt shy or uncomfortable about elaborating their answers when talking to the female interviewer.

Discussion of their personal lives elicited different responses depending on the gender of the interviewer. In-depth discussion on a given personal topic was noted whenever the interviewee and the interviewer were of the same gender. In responding to a question about his interest in sports, Rakan did not mention his interest in equestrian sports to the female interviewer but did talk about his personal experience with this sport with the male interviewer. He responded to the question, "Are you interested in sports?" to the female interviewer by saying the following:

"I have no interest in any competitive sport. I used to be interested in weight-lifting to build muscles." (Rakan, Interview Transcript, p. 29).

To the same question asked by the male interviewer, he responded as follows:

"I was interested in equestrian sports. I used to go the weekly horse races 
and I rode horses for a while and then I quit because I did not receive any encouragement in the field." (Rakan, Interview Transcript, p. 44).

Hana (a female participant) responded differently when each of the interviewers asked her about her opinion on the right of women to drive in Saudi Arabia (at the time of the study, women were not allowed to drive in Saudi Arabia). In response to the male interviewer, she answered by saying the following:

"I am a supporter, and I am waiting for that time." (Hana, Interview Transcript, p. 35).

In response to the female interviewer, her answer had more depth. For example, she talked about a classroom activity where her teacher had asked the students to predict what would happen by the year 2050. She reported that she had told her teacher and fellow female students that by 2050, women in Saudi Arabia would still not be allowed to drive. Additionally, she told the female interviewer that she was being sarcastic. Following this, she talked more about the controversy surrounding the topic.

Abeer (another female participant) responded to the questions on her interest in sports by referring to some aspects of her everyday life. She referred to the different activities that she and her friends would usually do. However, in response to the male interviewer, she said the following:

"I like to walk and run at the gym." (Abeer, Interview Transcript, p. 57).

With the male interviewer, Abeer, as can be seen in the excerpt above, did not talk about other activities or her friends. The female participants' attitudes here could be explained by the fact that, although they willingly agreed to be interviewed by a male interviewer, they gave short answers in an attempt to finish the interview quickly.

At the end of the second interview, each interviewee was asked by one of the interviewers (the male interviewer asked the male participants only, and the female interviewer asked the female participants only) whether there had been any differences in their responses to each of the interviewers' questions. The interviewees' first tended to respond by stating that there had been no difference in their responses and that the gender of the interviewer did not have any effect on the quality or quantity of their responses. However, further inquiry and analysis of the recorded responses revealed that there were, in fact, significant differences. Table 3 summarizes the results of the participants' responses concerning the last question. The final question asked by the interviewers was further explained, and participants were provided with some excerpts from their previous interview with the opposite gender that had shown some differences. Consequently, most of them (five participants) changed their answers and confirmed the differences in their answers for both interviewers. Lama, a female participant, was the only one who stood by the claim that her answers did not change for both interviewers. Notably, Lama works in a hospital laboratory, and in Saudi Arabia, this does not tend to not be as segregated as other workplaces. This could well be the reason for Lama having provided both interviewers with answers that were unaffected by their genders. 
Table. 3 Participants' answers to the last question of the interview

\begin{tabular}{cccc}
\hline Name & Gender & $\begin{array}{c}\text { Effect } \\
\text { (first answer) }\end{array}$ & $\begin{array}{c}\text { Effect } \\
\text { (after explanation) }\end{array}$ \\
\hline Rakan & M & No & Yes \\
\hline Murad & M & No & No \\
\hline Hana & F & No & Yes \\
\hline Hesham & M & No & Yes \\
\hline Abeer & F & No & Yes \\
\hline
\end{tabular}

Moreover, when Hesham was asked about his reason(s) for changing his answer when he was interviewed by the female interviewer, he said the following:

"I talked about my sisters so she could understand what I was saying quickly.” (Hesham, Interview Transcript, p. 6).

Here, we can see that Hesham is trying to use a different strategy. Using a different strategy could be justified insofar as it constitutes an attempt to deliver his ideas without the need for elaboration.

Finally, although the female interviewer approached approximately ten female participants to participate in this study, and though they agreed to be interviewed at the beginning, they seemed to be reluctant to take part when she told them that a male interviewer would interview them as well. Some of them expressed that they felt shy and that they would prefer to be interviewed by the female interviewer only. Owing to the fact that all the participants had to be interviewed by a female and a male interviewer, most female participants withdrew from participating in the study.

Hence, it can be said that the interviewer's gender had an effect on the discourse produced by the interviewees owing to the following indicators:

- Participants tended to talk at length about certain topics with the interviewer of the same gender and to give shorter answers or indicate their disinterest on the same topic with the interviewer of the opposite gender.

- Whenever the interviewee and interviewer were of the same gender, the interviewee was more prone to relaying personal experiences. 
- Numerous female participants refused to be interviewed by a male interviewer.

Consequently, this study provides an important opportunity to advance the understanding of the effect of interviewers' genders on the discourse produced by interviewees in Saudi Arabia. The findings of this study are consistent with those of Rapoport and Rapoport (1976), Lueptow et al. (1990), Huddy et al. (1997), and Altakhaineh et al. (2019) regarding the existence of such an effect. However, our findings contradict those of several other studies (for example, Johnson \& Moore, 1993; Huddy et al., 1997; O’Loughlin, 2002).

The types of effect elicited by gender in this study can be understood in terms of two main types. The first type of effect was that longer answers were provided when both the interviewer and the interviewee were of the same gender. This finding is different from the study conducted by Padfield and Procter (1996). The second type of effect was that female interviewees were more likely to feel that they had to take a defensive position regarding their ideas when interviewed by a male. Lama, for example, revealed the following:

"With the male interviewer, I felt I needed to defend my ideas, but with you (the female interviewer), I feel you would understand my position and ideas." (Lama, Interview Transcript, p. 73).

\section{Conclusion}

The investigation presented in this study reveals that the gender of the interviewer affects the discourse produced by the interviewees. The interviewees' responses differed in quality and quantity depending on their interviewer's gender. When both the interviewer and the interviewee were of the same gender, the responses to the questions were lengthy, and the interviewees expanded their discussion to other related topics. On the other hand, when both the interviewer and interviewee were not of the same gender, the interviewees replied in short answers and avoided answering questions by indicating their disinterest. Moreover, the interviewees' responses differed in depth as they discussed their personal experiences and everyday life activities depending on the interviewer's gender. In addition, most interviewees conceded that there was a difference in their answers to both interviewers depending on their gender dynamic.

There were two types of effect found in this study. The first one was that longer responses were provided if the interviewer and the interviewee were of the same gender. The second was that female participants tended to take a defensive position when interviewed by a male to express and defend their ideas.

\section{References}

Aboshaheen, S. (2020, February 8). 98\% of the students who have scholarships returned to the Kingdom. Makkah newspaper. https://makkahnewspaper.com/article/1503797

Alhojailan, A. I. (2015). Perceptions of academic writing by some Saudi graduate students 
studying in American universities. (Publication No. 10140161) (Doctoral dissertation, Oklahoma State University). ProQuest LLC.

Altakhaineh, A. M., AL-Tkhayneh, K. M., \& Rahrouh, H. (2019). The effect of the gender and culture of the IELTS examiner on the examinees' performance on the IELTS speaking test in the UAE context. International Journal of Arabic-English Studies, 19(1), 33-52. https://doi.org/10.33806/ijaes2000.19.1.2

Ballou, J., \& Del Boca, F. (1980). Gender interaction effects on survey measures in telephone interviews. Paper presented at the annual meeting of the American Association of Public Opinion Research, Mason, Ohio.

Blaydes, L., \& Gillum, R. (2010). Interviewer Effects in the Islamic World: Evidence from a Randomized Survey Experiment in Egypt. Paper read at American Political Science Association Annual Meeting, September 2-5, 2010, at Washington, D.C.

Brown, A. (2003). Interviewer variation and the co-construction of speaking proficiency. Language Testing, 20 (1), 1-25. http://dx.doi.org/10.1191/02655322031t242oa

Buckingham, A. (1997). Oral language testing: do the age, status and gender of the interlocutor make a difference? (Unpublished MA dissertation). University of Reading, Reading, United Kingdom.

Catania, J., Binson, D., Canchola, J., Pollack, L., \& Huack, W. (1996). Effects of interviewer gender, interviewer choice, and item wording on responses to questions concerning sexual behavior. Public Opinion Quarterly, 60, 345-375.

Coates, J. (2015). Women, men and language: A sociolinguistic account of gender differences in language. London: Routledge. DOI: https://doi.org/10.4324/9781315835778.

Curtis, W., Murphy, M., \& Shields, S. (2014). Research and Education: Foundations of Education Studies. London, England: Routledge. https://doi.org/10.4324/9781315858326

Galla, J. P., Frisone, J. D., Jeffrey, L. R., \& Gaer, E. P. (1981). Effect of experimenter's gender on responses to a sex-role attitude questionnaire. Psychological Reports, 49(3), 935-940.

Grimes, M., \& Hansen, G. (1984). Response bias in sex-role attitude measurement. Sex Roles, $10,67-72$.

Huddy, L., Billig, J., Bracciodieta, J., Hoeffler, L., Moynihan, P. J., \& Pugliani, P. (1997). The effect of interviewer gender on the survey response. Political Behavior, 19(3), 197-220.

Institute of International Education. (2014). Project Atlas: Trends and global data 2014. Retrieved from http://www.iie.org/Research-and-Publications/Project-Atlas

Johnson, T. P., \& Moore, R. W. (1993). Gender interactions between interviewer and survey respondents: Issues of pornography and community standards. Sex Roles, 28, 243-261.

Kane, E., \& Macaulay, L. (1993). Interviewer gender and gender attitudes. Public Opinion 
Quarterly, 57, 1-28.

Landis, J., Sullivan, D., \& Sheley, J. (1973). Feminist attitudes as related to sex of the interviewer. Pacific Sociological Review, 16(3), 305-314.

Lamb, M. E., \& Garretson, M. E. (2003). The effects of interviewer gender and child gender on the informativeness of alleged child sexual victims in forensic interviews. Law and Human Behavior, 27(2), 157-171.

Leedy, P. D., \& Ormrod, J. E. (2015). Practical research: Planning and design. Prentice Hall.

Locke, C. (1984). The influence of the interviewer on student performance in tests of foreign language oral/aural skills. (Unpublished Master's thesis). University of Reading. Reading, United Kingdom.

Lueptow, L. B., Moser, S. L., \& Pendleton, B. F. (1990). Gender and response effects in telephone interviews about gender characteristics. Sex Roles, 22(1-2), 29-49.

Lumley, T., \& O'Sullivan, B. (2005). The effect of test-taker gender, audience and topic on task performance in tape-mediated assessment of speaking. Language Testing, 22(4), 415-437. http://dx.doi.org/10.1191/02655322051t303oa

Mackey, A., \& Gass, S. M. (2005). Second language research: Methodology and design. Mahwah, N.J.: Lawrence Erlbaum

Miles, M. B., \& Huberman, A. M. (1994). Qualitative data analysis: An expanded sourcebook (2nd ed.). Thousand Oaks: Sage Publications.

Motallebzadeh, K., \& Nematizadeh, S. (2011). Does Gender Play a Role in the Assessment of Oral Proficiency? English Language Teaching. 4(4), 165-172. http://dx.doi.org/10.5539/elt.v4n4p165

Namaziandost, E., Abedi, P., \& Nasri, M. (2019). The Role of Gender in the Accuracy and Fluency of Iranian Upper-intermediate EFL Learners' L2 Oral Productions. Journal of Applied Linguistics and Language Research, 6(3), 110-123.

O'Loughlin, K. (2002). The impact of gender in oral proficiency testing. Language Testing, 19(2), 169-192. https://doi.org/10.1191/02655322021t226oa

O’Sullivan, B. (2000). Exploring gender and oral proficiency interview performance. System, 28(3), 373-386.

Padfield, M., \& Procter, I. (1996). The effect of interviewer's gender on the interviewing process: A comparative enquiry. Sociology, 30(2), 355-366.

Porter, D. (1991). Affective factors in the assessment of oral interaction: gender and status. In Arnivan, S. (Ed.) Current developments in language testing. Anthology series 25 (pp. 92-102). Singapore: SEAMEO Regional Language Centre.

Rapoport, R., \& Rapoport, R. N. (1976). Dual-Career Families Re-Examined. New York: Harper and Row. 


\section{Macrothink}

International Journal of English Language Education

ISSN 2325-0887 2020, Vol. 8, No. 2

Rubin, H., \& Rubin, I. (2005). Qualitative interviewing: The art of hearing data (2nd ed.). Thousand Oaks, CA: Sage Publication.

Saygin, P. O. (2019). Gender bias in standardized tests: evidence from a centralized college admissions system. Empirical Economics, 1-29. https://doi.org/10.1007/s00181-019-01662-z

\section{Copyright Disclaimer}

Copyright for this article is retained by the author(s), with first publication rights granted to the journal.

This is an open-access article distributed under the terms and conditions of the Creative Commons Attribution license (http://creativecommons.org/licenses/by/3.0/). 